\title{
Comerciantes de sentidos: um olhar para a formação visual dos educandos
}

Ireno Antônio Berticelli*

Claudia Aparecida dos Santos ${ }^{* *}$

Valdecir Smaniotto ${ }^{* *}$

\section{Resumo}

Este artigo se propóe investigar as possibilidades que a cultura visual oferece na constituição das identidades, na contemporaneidade. Estuda o fenômeno imagético quanto a seu potencial dialógico familiar aos jovens, sobretudo como uma nova e adequada forma de acesso ao conhecimento e, por consequência, à educação formal e não formal em que se entende a cultura da imagem como campo que abre novas possibilidades pedagógico-educativas. Este estudo objetiva, ainda, contribuir para que os educandos possam assumir papel ativo no contexto do complexo mundo da imagem que diuturnamente envolve os sujeitos em suas práticas sociais. Seguimos a perspectiva teorética da cultura visual de conformidade com alguns dos mais destacados autores da área. Conclui-se que uma educação contemporânea em todos os níveis e formas requer formação para a compreensão/leitura adequada das imagens sob as suas mais variadas formas pelas quais são produzis e veiculadas, tal é sua força simbólica que contribui na formação dos sujeitos.

Palavras-chave: Educação. Cultura visual. Formação pela imagem.

\footnotetext{
* Doutor em Educaçáo pela Universidade Federal do Rio Grande do Sul (UFRGS). Professor da Universidade Comunitária da Região de Chapecó (UNOCHAPECÓ).

${ }^{* *}$ Mestra em Educação pela Universidade Comunitária da Região de Chapecó (UNOCHAPECÓ).

*** Mestre em Educação pela Universidade Comunitária da Região de Chapecó (UNOCHAPECÓ). Professor da Escola de Educação Básica Marechal Borman, em Chapecó, SC.
} 


\section{Considerações introdutórias}

A relevância da visão e da visualidade no mundo contemporâneo impulsiona o surgimento de um novo campo de estudo: a cultura visual. Trata-se de uma estrutura compreensiva fluida, que intenta a análise e entendimento nas relaçóes cotidianas dos sujeitos com os vários media visuais. Ao mesmo tempo, trata-se de um desdobramento da cultura em si. No entanto, as discussóes que cercam seu entorno assumem caminhos labirínticos, por se tratar de uma área teórica que não encontra respostas fáceis, surgida na década de 90 do século passado, ao lado dos Estudos Culturais. Os estudos visuais evidenciam o caráter de mudança, caro aos que pensam a pós-modernidade, o que faz deste um campo relevante de sinalização pelo qual adentramos a novos territórios na análise da subjetivação pela imagem.

Ao destacar, na pós-modernidade, o caráter efêmero, mutante e híbrido como características fundantes, as representaçôes visuais igualmente também o assumem. Sendo assim, as dificuldades em teorizar acerca da cultura visual se póem na mesma medida que tentar elucidar a pós-modernidade. Todavia, entendemos a cultura visual como uma das importantes facetas que compóem o que chamaremos pós-modernidade, reconhecendo no campo da visualidade as formulaçóes primordiais do que constitui a formação de como recepcionamos e configuramos o mundo no qual vivemos.

Os estudos da Cultura Visual ou Estudos Visuais (HERNANDEZ, 2007) discutem e tratam a imagem não apenas pelo seu valor estético, mas, sobretudo, buscam compreender o papel social da imagem na vida da cultura, não se restringindo nem aos fenômenos, nem aos seus conteúdos, uma vez que também está interessada em refletir sobre a experiência dos sujeitos na cultura.

Pensar a respeito da visualidade e as consequentes relaçóes que se articulam em seu entorno - o uso da imagem em contextos sociais -, que quando cunhadas e absorvidas pelas culturas, conscientemente ou não, vemos deflagrada, aí, a presença íntima de uma possível relação entre formas de poder e a constituição dos sujeitos. Nessa perspectiva, podemos asseverar que a empiria se dá mediada pelos signos. Faz-se também importante sublinhar que aquilo que as imagens dizem não é pouco, sendo capazes de ressignificar olhares e maneiras de interpretar o mundo.

Reconhecendo a cultura visual como formadora de identidades e também como mediadora de experiências e conhecimentos na pós-modernidade, 
pensar as imagens, analisando-as em seus significados e significantes culturais, considerando, para tanto, as relaçôes culturais que estão imbricadas em tal processo que formulam a representação do real e dão às imagens a função de apresentá-lo, denotam-se claramente as relaçóes de poder que se assentam em tal processo. As imagens, neste contexto, assemelham-se a dispositivos (FOUCAULT, 2000), que, quando arraigadas às práticas sociais, tornam-se objetivadoras das formas de ver e produzir olhares, assumindo um importante papel na formação identitária dos indivíduos, sobretudo das novas geraçóes.

Para Foucault (2000, p. 244), o conceito de dispositivo pode ser definido como:

[...] um conjunto decididamente heterogêneo que engloba discursos, instituiçóes, organizaçóes arquitetônicas, decisóes regulamentares, leis, medidas administrativas, enunciados científicos, proposiçóes filosóficas, morais, filantrópicas. Em suma, o dito e o não dito são os elementos do dispositivo. O dispositivo é a rede que se pode tecer entre estes elementos.

Contemporaneamente, nos dobramos ao reconhecimento de que vivemos submersos em um oceano de imagens. Diante da profusão de imagens, estas se caracterizaram como elemento axial da pós-modernidade. No sentido preconizado por Foucault (2000), elas se tornam dispositivos de relevante imponência sobre as individualidades.

Não é para menos: os humanos, desde os primórdios, viram-se na necessidade da construçáo de signos representativos de realidades nas quais viviam. Muitos desses signos foram materializados em imagens. Com o passar dos tempos, as imagens adquiriram status de representação da ideia de mundo em sua totalidade. Exemplo disso são as catedrais da época medieval: representativas da totalidade de mundo, garantidoras da ideia de perenidade e autossuficientes em representaçóes imagéticas.

De maneira análoga às catedrais medievais, os shoppings centers, embora hoje não mais representem a ideia perenidade - mas sim a fluidez -, são, talvez, a manifestação e a representação da totalidade e autossuficiência imagética. Além destas, existe a midiatização forçada pelos meios de comunicação de massa, especialmente a televisão, por sua popularidade, que através de suas 
programaçóes atinge e influencia grande parte da população mundial, sem falar, ademais, da penetração imagética gerada pelo uso da internet.

Autores como Mirzoeff (2003) sinalizam para o destacado papel da tecnologia na formatação de um modelo de visualidade na contemporaneidade, capaz de promover a visão como um sentido hegemônico. Dessas representaçóes imagéticas decorrem muitos dos sentidos e significados dados ao cotidiano, especialmente pelos jovens educandos, haja vista que os dispositivos "[...] devem sempre implicar num processo de subjetivação, isto é, devem produzir o seu sujeito" (AGAMBEM, 2009, p. 38).

As representações imagéticas vinculam-se a contextos, significados e experiências, não existindo aleatoriamente. Também não podem ser lidas sem alguns tipos de associaçôes, sejam estas sociais, políticas, religiosas ou econômicas, em níveis aprofundados ou superficiais. Sendo assim, a reflexão sobre as analogias de poder que se articulam, usando como meio de propagação e disseminação de seu discurso nas imagens exige: mais do que refletir sobre estas imagens, pensar onde se amarram as estruturas que atuam no processo de objetualização do ato de ver. Já que "[...] apesar de visão sugerir o ato de ver como uma operação física, e visualidade o ato de ver como um fato social” (FOSTER, 1998, apud MIRZOEFF, 2003, p. 54), de acordo com Hal Foster, mesmo ambos não sendo opostos, cabe reconhecer que são processos singulares em cada sujeito que vê, compreende e reconhece a partir de um contexto.

Assim, a busca de entender como as imagens desembocam na constituição do indivíduo e compóem sua subjetividade, decorre em analisar as imagens em seus possíveis processos formativos, sobretudo na tentativa de alcançar em que medida as imagens provocam a apreensão e interpretação do mundo.

No cenário da pós-modernidade, o conceito de poder apresentado por Foucault (1979), a nosso ver, é central para o entendimento das imagens enquanto constituintes de valores e atitudes. Ao analisar as imagens como dispositivos (FOUCAULT, 2000) capazes de ampliar as relaçóes de diálogos e trocas entre os sujeitos, vemos nelas uma potente forma de poder. Contudo, o poder, como nos foi apresentado por Foucault (2000), não é unilateral, póe-se no processo de negociação, visto que os espectadores, ou os que veem o exercem quando observam e interpretam as imagens.

Na tentativa de alcançar o que chamaremos, aqui, de fenômeno visual, e entender o forte apelo que as imagens midiáticas exercem na vida das pessoas, 
fazemos um breve regresso, no intento de reconhecer como este processo se iniciou. Buscamos no caso da menina de 13 anos, Omayra Sanchez, em 1985, que muitos veem como o começo do que hoje chamamos globalizaçáo midiática, ou entáo um acontecimento que demarca a assunçáo hegemônica da imagem. A menina Omayra teve sua agonia apreciada em tempo real pelas câmaras de televisão de todo o mundo, por três dias, até sua morte por gangrena, tendo tido as pernas e parte do tronco soterradas pelo vulcáo Nevado del Ruiz, na Colômbia. Enquanto o mundo acompanhava ao vivo, do sofá, este lamentável e tristíssimo infortúnio, a cultura da sociedade do espetáculo (DEBORD, 2005) se solidificava. A vida privada tornou-se cada vez mais pública, fortalecida pela ânsia de ver ou de ser visto.

As projeçóes que procuram compreender o fenômeno visual na pósmodernidade apontam para a cultura midiática, na qual a sensação de estar sendo visto, vigiado, amolda os indivíduos em sua constituição identitária, suas formas de relacionamentos, sendo capazes de orientar os jovens na apreensão dos novos saberes, refletindo sobre suas expressóes e subjetividade, enfim, estruturando os processos que formatam a sociedade contemporânea.

Assistimos a uma proliferaçáo de textos e imagens que atingem os vários níveis sociais num borramento das fronteiras do real. Inaugura-se um novo lugar de aprender incessante e múltiplo em seus meios e canais: "[...] a informática retira o texto da escrita e o faz 'deslizar' pelas ondas curtas das telecomunicaçóes, à velocidade da luz, para disponibilizá-lo em inumeráveis lugares" (BERTICELLI, 2010, p. 26). Da mesma maneira o faz com as imagens. Tudo está ao alcance de um toque.

O caráter fluido e instável das identidades, o espelhamento da vida social no espetáculo, a centralidade dos interesses no consumo e a crescente estetizaçáo do quotidiano direcionam a novos usos e adaptaçōes dos recursos tecnológicos. À luz deste contexto, podemos acreditar que Berticelli (2010) considera o lugar do texto, o lugar da imagem, também como o massivo uso das tecnologias, como lugares do aprender, onde o virtual pode converter-se no real "formatável ad infinitum", tanto fisicamente quanto simbológico.

Sendo assim, pode-se dizer que o foco da cultura midiática é a produção e reproduçáo de sentidos em contextos culturais que ganham força e tomam uma super-dimensão quando lançados na cultura, pois uma vez na cultura, formam-se estruturas que habitam arbitrariamente o imaginário e operam ativamente para a sua colonização. Vejamos isto no caso da publicidade, 
que é hoje o espelho pelo qual todos querem ser vistos (ou muitos almejam sê-lo). Seu poder é tamanho que detém a capacidade de legitimar qualquer coisa que lhe passe. Nela tudo está à venda: os objetos, as pessoas, a beleza, as desgraças... Dessa forma, ela dita os modelos a serem seguidos e estabelece a nova ordem.

Baudrillard (1991) sinaliza para o desaparecimento das fronteiras que separavam ficção e realidade. À luz deste cenário, aferimos como a vida cotidiana se estrutura na busca de entendimento do papel da imagem na construçáo destas realidades, que incontáveis vezes têm suas açôes condicionadas à prática do ver e ser visto. Os processos que fundamentam os novos paradigmas sociais muitas vezes são o resultado do encontro das imagens com as mídias em perfeita simbiose, cujos frutos são a midiatização da vida, a estetização do cotidiano e o consumo incontrolável de vontades. A partir das análises de Baudrillard (2005), entende-se que na cultura pós-moderna não são as imagens que refletem a sociedade e, sim, o contrário: a sociedade é que se espelha nas imagens,também alcunha para os novos modos de vida pautados nas imagens, caracterizando-os simulação ou simulacro do real.

\section{Vendedores de lentes, comerciantes de sentidos: mídia e consumo}

À luz dessas disposiçôes, ao pensar nas relaçôes que estão implicadas na disseminação das imagens, estaríamos falando de uma possível aproximação dos lugares onde os indivíduos encontram suas referências, entendendo-os como "lugares do aprender" (BERTICELLI, 2010). Atualmente, mais do que por escolas ou famílias, as crianças e jovens sấo acompanhadas cotidianamente por computadores, televisores e mídias sem responsabilidades imputáveis, salvo in extremis. As famílias, por diferentes motivos, ausentam-se, a escola se arrasta decrépita na tentativa de realizar a construção subjetiva dos educandos.

Dialogamos com Baudrillard (1991, 2005), Bauman (1999, 2001, 2008, 2010, 2013), Hernandez (2000, 2007), Foucault (1979, 1999, 2000), entre outros, a fim de problematizar as relaçôes dos indivíduos com os novos saberes e com as novas expressóes de subjetividade, reconhecendo a possibilidade de estarmos envoltos por uma "cultura visualmente orientada" (SAUNDERS, 1984): campo ainda aberto à investigação, mormente à investigaçáo relacionada à educação. 
A primeira fase do capitalismo, ainda na modernidade, é marcada substancialmente pelo trabalho fabril e, sobretudo, pela produção, na qual o consumo era o destino da produção (embora neste momento já tenha adquirido centralidade na vida de algumas pessoas de classe média ou alta). Após a revoluçáo industrial e o avanço tecnológico e midiático, aliados às transformaçôes sociais e culturais, a racionalidade inverteu-se: deixou o consumo de ser apenas mais um componente do modelo produtivista e passou a ser instaurado, gradualmente, como um processo cultural, inaugurando, entáo, o capitalismo de consumo. A racionalidade da produçáo cedeu lugar à racionalidade do consumo. Dessa forma, podemos dizer com Bauman (2010) que se outrora era a demanda que condicionava a produção, agora é a produção que determina a oferta, ou seja, a produção massiva e a criação de necessidades induzem ao consumo como representaçóes significantes. $\mathrm{O}$ que move o consumo não é a necessidade, mas o desejo fundado na pregação discursiva e representativa de que é necessário estar on. Sobretudo nestes nossos dias, o consumo já náo se dá exclusivamente pelo desejo, muito menos por necessidade, mas, sim, por compulsividade face ao constante apelo das imagens e pela referência que temos na imagem do outro. $\mathrm{O}$ modelo moderno de produçáo náo dá mais conta totalmente de nossas necessidades, mas não temos ainda um modelo a seguir. $\mathrm{O}$ modelo mercantil, de criaçáo de novos desejos e novas necessidades que induz ao consumo tem sido um desses protótipos contemporâneos utilizados para nos subjetivar.

Julgamos importante retratar este momento da história, pois guarda em si um importante relato sobre os rumos que tomaram as sociedades e seus membros. Frente ao cenário de instabilidade onde a mídia se propóe como um meio educativo e orienta massivamente para o consumo, vê-se como resultado deste encontro mídia-consumo, um potente criador dos significados simbólicos entendidos, aqui, como atuais regentes da sociedade, que dão, entấo, ao capitalismo a hegemonia do poder.

O mote do consumo está na aparente imagem de poder que este oferece. Baseia-se no excesso, no desperdício e, consequentemente, na frustração. Tratase de produzir desejos inadiáveis, que possam ser consumados com urgência e depois, mais e mais, na ânsia de completar-se com objetos capazes de trazer felicidade. $\mathrm{O}$ consumo sempre fez parte da vida humana, mas a sociedades capitalistas inauguram o consumismo. Nesse sentido, "[...] a satisfação deve ser apenas uma experiência momentânea, algo que, se durar muito tempo, deve-se temer, e não ambicionar" (BAUMAN, 2008, p. 126). 
O consumismo caminha sobre os pés da imagem de Marketing e se alimenta da insatisfação pessoal determinada pela obsoletização de tudo que há. Como diria Steiner (1990, p. 159), "Os meios audiovisuais de mass media são calculados para impacto máximo e obsolescência imediata”, abrigado na subjetividade das valoraçóes. Assim, o valor simbólico do ato de comprar, consumir e descartar é, hoje, a real medida de valor aceita pela sociedade.

Jean Baudrillard (2005), nascido em 1929, e tendo vivido estas transformações sociais, apresenta um estudo de grande relevância, quando trata da sociedade de consumo. Procede, em sua crítica à economia política, não mais pelo viés da produtividade como fez Marx, mas a partir do consumo.

Considerando como os usuários entram na regra do jogo, cedendo às exigências a eles impostas pela mídia, na tentativa de responder às circundantes questôes do nosso tempo, recorremos, inicialmente a Baudrillard (2005). Para o autor, o principal instrumento de manutenção do sistema econômico vigente é a disseminação do consumismo como um modo de vida.

Para Baudrillard (2005), o consumo surge como um sistema que assegura a integração dos grupos, e formula um aparelho de significaçóes, valores e uma forma de linguagem. Para o autor, "[...] o consumo define-se como exclusivo do prazer” (BAUDRILLARD, 2005, p. 78). Trata-se de um sistema generalizado de trocas, onde nunca se está sozinho. Todos os que consomem estão implicados e envoltos por discursos. "A propósito, também podemos já definir o lugar do consumo: é a vida quotidiana” (BAUDRILLARD, 2005, p. 25).

Segundo o autor, todas as sociedades consumiram acima de suas necessidades. Vê na mídia a "incentivadora do consumo", com a responsabilidade de cumprir este desígnio e, para isso, utiliza espertamente as fraquezas e vaidades humanas. Hoje, entende-se a cultura do consumo que se concretiza em meio à cultura em geral, numa simbiose entre o consumo e mídia, o que torna impossível outro modo de vida, principalmente se considerarmos o modelo político-econômico vigente. Se Marx (2008), para a sociedade balizada na produção, entendeu que os propósitos das vidas estavam limitados à capacidade produtiva, na sociedade do consumo está na capacidade de consumir signos (BAUDRILLARD, 2005).

Bauman (2008) expressa de maneira contundente a relação de consumo entre aqueles que numa perspectiva moderna seriam definidos como sujeito e objeto. Contudo, essa caracterização moderna de sujeito que consome 
deixa de fazer sentido na fluidez contemporânea onde cada qual é ao mesmo tempo ambivalente: consumidor e consumido. Nas palavras de Bauman (2008, p. 20):

Na sociedade de consumidores, ninguém pode se tornar sujeito sem primeiro virar mercadoria, e ninguém pode manter segura sua subjetividade sem reanimar, ressuscitar e recarregar de maneira perpétua as capacidades esperadas e exigidas de uma mercadoria vendável. A "subjetividade" do "sujeito", e a maior parte daquilo que essa subjetividade possibilita ao sujeito atingir, concentrase num esforço sem fim para ela própria se tornar, e permanecer, uma mercadoria vendável. A característica mais proeminente da sociedade de consumidores ainda que cuidadosamente disfarçada e encoberta - é a transformação dos consumidores em mercadorias [...].

Na perspectiva apontada pelo sociólogo, é o consumo que compóem os meandros em que se processa a vida e em que se constituem os sujeitos nas sociedades capitalistas.

Baudrillard (2005), nos estudos que desenvolveu sobre o acordo das mídias e das tecnologias no modo de vida capitalista, identifica uma tênue linha que permeia a relação consumo e mídia. A difusão de desejos efêmeros, a competitividade e o imediatismo como características balizadoras da cultura midiática dissolve a imagem do real, dita as referências e guarda o lugar onde cada indivíduo deve propor-se cegamente a chegar. Para ele, a publicidade constitui um lugar estratégico, "[...] transforma os objetos em acontecimento" (BAUDRILLARD, 2005, p. 134). Para ilustrar este fenômeno, basta lembrar que o lançamento de um novo tablet pode ser aguardado por multidão, no mundo inteiro, que depois vão se aglomerar nas lojas para poder apropriar-se sofregamente desse modelo top, porém, por pouco tempo. Náo tarda que novo modelo lança a este último na obsolescência.

Todavia, sinaliza, ainda Baudrillard (2005, p. 134-135), que “[...] a verdade é que a publicidade e o restante dos mass media não nos ilude”, pois esta "[...] encontra-se para lá do verdadeiro ou do falso [...]". Ao dizer que não somos passivamente iludidos por imagens midiáticas, publicitárias, sejam quais forem, podemos entender que alude aos mass media, genericamente, relacionando-os a 
dispositivos de poder, e que estes compreendem todas as tensóes que amarram tal processo em uma pulverizaçáo de interesses, significados e valores.

A massificação e, ao mesmo tempo, a dissolução dos indivíduos caracterizam ilustrativamente a sociedade da informação, heterogênea, líquida, escrita na urgência e superada constantemente, num processo ininterrupto de invenção da imagem ideal (realidade simulada) e a busca em alcançá-la (simulaçôes). "Vivemos desta maneira ao abrigo do signo e na recusa do real” (BAUDRILLARD, 2005, p. 25). Resta perguntar se assim fazemos voluntariamente.

$\mathrm{Na}$ busca de entender o que se passa, os simulacros e simulaçóes apresentados por Baudrillard (1991), podem ser, nesse sentido, um importante aliado no ensaio de reconhecer os meios nos quais os indivíduos encontram suas referências e se constituem como sujeitos.

$\mathrm{O}$ acesso e permanência do interesse do jovem em campos imagéticos, as relações virtuais pautadas apenas em imagens não se referem à mera sobreposição de imagens. Pode-se dizer que se instaura aí um novo princípio de vigilância que se assemelha ao panóptico de Foucault (1977) em Vigiar e punir. Mas já não se trata de um olhar palpável e centralizado. Quando Foucault (1977) define o panoptismo como dispositivo de vigilância, o determina concretamente. $\mathrm{O}$ panóptico, dessa vez, não é mais uma imposição. Os indivíduos inscrevem-se por conta própria, inserindo-se no sistema de vigilância, na busca do olhar dos outros sobre si e, ao mesmo tempo, desejam o passaporte para vigiar o outro. $\mathrm{O}$ atual panóptico não se caracteriza mais em "ver sem ser visto" (DELEUZE, 2005 , p. 43), mas para isso precisa que os vigiados ou vigilantes se submetam voluntariamente às regras imposta pelo jogo. Dessa forma, se pensarmos com Foucault (1977), os próprios indivíduos assumem um papel ativo em sua própria vigilância.

Bauman (1999, p. 60) acredita que "[...] o panóptico forçava as pessoas à posição em que poderiam ser vigiadas. $\mathrm{O}$ sinóptico não precisa de coerção agora este induz as pessoas à vigilância”. Em recente obra intitulada Vigilância líquida, Bauman (2013) esclarece aspectos corriqueiros da vida dos jovens em suas relaçóes midiáticas. Diz ele:

A essência das redes sociais está no intercâmbio de informação pessoal. Os usuarios alegram-se com "revelar detalhes íntimos de sua vida pessoal”, "sobrepassar 
informação detalhada" e "compartilhar fotografías". Estima-se que 61 por cento dos adolescentes britânicos entre 13 e 17 anos apresentam um perfil pessoal numa rede social que lhes permite "socializar em série" (BAUMAN, 2013, p. 37) ${ }^{1}$.

Em larga escala, a autoimagem construída em perfis na internet já não diz respeito à realidade; talvez Bauman, em diálogo com Baudrillard, anunciaria que a simulação está em parecer ser, a fim de promover-se como objeto e poder ser vendido também como mercadoria.

A conjuntura na qual os adolescentes brasileiros estão imersos não foge das observações de Bauman (2013) em relação aos jovens britânicos. Talvez a utilização dos recursos midiáticos como as redes sociais esteja mais visceralmente presente na vida dos jovens brasileiros, já legitimadas como um dos inumeráveis "lugares do aprender" (BERTICELLI, 2010). Os discursos produzidos pela televisão, pela internet, pelas mídias de modo geral, inauguram uma nova forma de poder que se dá, conforme Foucault (1979), numa tensão de forças, na ação sobre ações. Mas, invariavelmente, estão, de alguma forma, refletidas nas identidades. E estes "lugares", na visão de Berticelli (2010), merecem ser pensados pela escola, pois esse megafenômeno já está lá.

Atualmente, crianças são orientadas por computadores, televisores e outras mídias sem responsabilidades. E ainda que estejamos vivendo a lógica do sujeito fragmentado, parece existir um esforço para que a dialética da construção identitária seja ainda linear, e o sinóptico (BAUMAN, 1999) vem a fim de manter a ordem, atuando na construção e subjetivação do indivíduo.

Nas sociedades contemporâneas balizadas pela divulgação da própria imagem, as relaçóes humanas também são caracterizadas como objetos do consumo. O juízo das açóes de consumo opera como importante promotor de significados culturais e identitários, alcançando lugares que vão além de sua dimensão material e objetiva, configurando-se como um campo de entendimento onde as representaçôes simbólicas e suas contingências acionam a cultura. Para Baudrillard (2005, p. 208), “O consumo constitui um mito. Isto é revela-se como palavra da sociedade contemporânea sobre si mesma; é a maneira como a nossa sociedade fala”. E esses falares ainda não se constituíram objeto de conhecimento, no grau necessário, no cotidiano dos processos educativos institucionalizados. Há um fosso profundo entre o cotidiano dos usuários 
desses falares e as instituiçôes educacionais. É mais cômodo ordenar "Fechem os notebooks" ou "Guardem os tablets" que integrar esses meios ao cotidiano do ensinar e do aprender.

$\mathrm{Na}$ sociedade dos símbolos, como já mencionamos, amparados por Baudrillard (1968), o objeto perdeu o seu valor de uso e o seu valor de troca, para assumir uma função. A dimensão sígnica fez com que o valor de uso dos objetos fosse perdido em benefício do valor simbólico, que serve bravamente ao sistema capitalista e a um fim mercadológico. Assim sendo, o interesse despendido para a imagem não habita mais as pessoas ou os objetos, mas, sim, o sistema de signos que o reflete (BAUDRILLARD, 1991, 2005). A imagem associada ao consumo resulta na ampliação deste potencial dialógico e, usada como dispositivo, portanto, apresenta uma representação que detém discursos que operam nas relaçóes de poder e formulam orientaçóes das mais diversas.

À luz desta reflexão, não tememos o erro ao aludir que os milhares de jovens que compóem suas identidades como em um jogo de montar, apenas considerando a imagem que querem propor de si, convencidos pelas narrativas visuais que se apresentam, almejam, mesmo que momentaneamente, a satisfação e o pertencimento nisto que Baudrillard (1991) chamou de simulacros, em sua obra Simulacros e simulaçóes.

Nessa perspectiva, muito mais do que construir uma identidade, imersos num consumo frenético motivado também pelas imagens, o sentido é dado superficialmente ao se consumir uma identidade. Para exemplificar, poderíamos citar a influência midiática no consumo de gadgets relacionados ao pertencimento a um clube de futebol, ou a itens de marcas multinacionais. Talvez Bauman (2007) esclareça essa constituição das identidades temporárias. Para ele,

A resposta à questão relativa à sua identidade não é mais um "engenheiro da Fiat (ou da Pirelli)", ou um "servidor público", ou um "mineiro" ou um "gerente de loja da Benetton", mas, como num recente comercial descrevendo uma pessoa que usaria o prestigioso logotipo nele anunciado, alguém que "adora filmes de terror, bebe tequila, usa saiote escocês, é fã do Dundee United F.C., da música dos anos 1980, da decoração dos anos 1970, viciado nos Simpsons, cria girassóis, a cor favorita é o cinza-escuro, fala com as plantas". No número seguinte 
da revista, aparece outra pessoa [...]. Os dois "atestados de identidade" levam à mesma conclusão: "tudo está no detalhe". Desnecessário dizer que todos os detalhes mencionados e qualquer outra coisa mencionável estão disponíveis nas lojas. (BAUMAN, 2007, p. 114-115).

O consumidor, incitado pelas mídias, tem sua obrigação associada não mais à utilidade específica do objeto e, sim, ao comércio simbólico, relacionado invariavelmente à capacidade de significar. Assim, “[...] a sociedade de consumidores representa o tipo de sociedade que promove, encoraja ou reforça a escolha de um estilo de vida e uma estratégia existencial consumistas, e rejeita todas as opçóes culturais alternativas" (BAUMAN, 2008, p. 71).

As imagens pertencem ao universo mais antigo da vida humana. Porém, jamais as representaçóes imagéticas foram produzidas e difundidas como na era contemporânea. Para Roland Barthes (1990), as imagens compóem-se sob uma natureza linguística e abarcam significados que vão além da função de expor a cópia. A elas conferem-se grande destaque como condensadora de olhares e formadora de opinióes.

Assim como foi com as marcaçóes rupestres, o fascínio pelas imagens das catedrais, nas fotografias que marcaram a história das guerras, o triste caso da menina Sanches que citamos no início de nosso texto, as relações de trocas dos indivíduos com mundo carregam em si uma rede de códigos determinantes do que vemos e como queremos ser vistos. Isso, porque a experiência pelos sentidos se dá mediada pelos signos que nos compóem e, estes sim, orientam os sujeitos nas formas de ler os vários códigos que lhe são emitidos, em processos simultâneos de compreensão e apreensão.

As formas de fruição de imagens no contemporâneo ainda suscitam as tensôes que todo jogo de poder abarca, todavia não é mencionado o caráter unilateral na leitura e interpretação das imagens por este simplesmente não existir. Para Hernandez (2000), um referencial, em se tratando de estudos sobre cultura visual, fala em "compreensão crítica”. É importante dizer que para isso não se fundamenta em valoraçóes ou juízos individuais. Os estudos visuais dirigem-se para a análise das imagens como representação visual provenientes de produçáo de sentidos em contextos culturais.

Sendo assim, o conteúdo da Cultura Visual não corresponde apenas às imagens, objetos ou lugares, mas também à experiência dos sujeitos, uma vertente 
que é abrangida pela dimensão pedagógica. Acompanhamos o pensamento de Campos (2002, p. 108), para quem: "Interpretar o mundo visual, significa perceber [...] também o meio em que elas [as imagens] se inserem".

A busca dos estudos voltados para a visualidade, o esquadrinhamento dos meios nos quais as imagens estáo inseridas e o reconhecimento dos fins a que servem póe em realce o enfoque do papel da visualidade na atualidade. As novas necessidades da educaçáo em tempos de incertezas, assim como a importância em promover nos educandos a compreensão de valores estéticos e éticos compreende a formação crítica e participativa dos espectadores da cultura visual.

\section{Considerações finais}

Não pretendemos, com este estudo, julgar e sentenciar sobre o uso das imagens na formação dos jovens. Procuramos chamar a atenção para a condição silenciosa e cotidiana em que as imagens penetram na construção subjetiva dos educandos. E alertamos, assim, para o reconhecimento da necessidade de encarar a cultura visual como sendo potencialmente capaz de auxiliar no processo de interpretação e consequente reflexão do uso destas mesmas imagens na cultura.

Nesse sentido, acreditamos que esta análise possa tanto se constituir como um veículo para o entendimento da cultura visual no cotidiano como, também, favorecer o caráter de crítica no uso e na recepção inconsciente das imagens, podendo, desse modo, participar da constituição de um novo sujeito de conhecimento, na era da imagem.

Quando refletimos sobre as ações humanas na pós-modernidade, vemos nitidamente a cultura do consumo, que se agarra a mecanismos de sedução, modos de vida e subjetivação, na incitação de novos desejos e necessidades inventadas pela competitividade própria do capitalismo, e os propaga pelos meios midiáticos, em forma de imagens, movimentando a vida em uma contínua roda de simulação, movida no simples ato de ver. Sendo assim, o uso das imagens para fins mercadológicos merece atenção.

Assim, como afirma Fernando Hernández (2007, p. 43), “[...] a importância do reconhecimento dos códigos visuais de nossa sociedade, dentro da escola, é fundamental para que os alunos não permaneçam 'indefesos' diante de todas estas informaçôes que se apresentam”. Esta é também a preocupação que nos moveu. 


\section{Nota}

${ }^{1}$ A tradução do original em língua espanhola é de responsabilidade dos autores do artigo.

\section{REFERÊNCIAS}

AGAMBEM, Giorgio. O que é o contemporâneo? E outros ensaios. Chapecó, SC: Argos, 2009.

BARTHES, Roland. O óbvio e o obtuso. Rio de Janeiro: Nova Fronteira, 1990.

BAUDRILLARD, Jean. O sistema dos objetos. São Paulo: Perspectiva, 1968.

BAUDRILLARD, Jean. Simulacros e simulaçôes. Lisboa: Relógio

D'água, 1991.

BAUDRILLARD, Jean. A sociedade de consumo. Lisboa: Edições 70, 2005.

BAUMAN, Zygmunt. Globalização: as consequências humanas. São Paulo: Jorge Zahar, 1999.

BAUMAN, Zygmunt. Modernidade líquida. Rio de Janeiro: Zahar, 2001.

BAUMAN, Zygmunt. Vida líquida. Rio de Janeiro: Zahar, 2007.

BAUMAN, Zygmunt. Vida para o consumo: a transformação das pessoas em mercadoria. Rio de Janeiro: Zahar, 2008.

BAUMAN, Zygmunt. Capitalismo parasitário. São Paulo: Jorge Zahar, 2010.

BAUMAN, Zygmunt. Vigilancia liquida. Barcelona: Paidós, 2013.

BERTICELLI, Ireno Antônio. Educação em perspectivas epistêmicas pósmodernas. Chapecó, SC: Argos, 2010.

CAMPOS, Neide Pelaez. A Construção do olhar estético-crítico do educador. Florianópolis, SC: Editora da UFSC, 2002.

DEBORD, Guy. A sociedade do espetáculo. Tradução de Estela dos Santos Abreu. Rio de Janeiro: Contraponto, 1997. 
DELEUZE, Gilles. Foucault. Tradução de Cláudia Sant'Ana Martins. São Paulo: Brasiliense, 2005.

FOUCAULT, Michel. Vigiar e punir: nascimento da prisão. Petrópolis: Vozes, 1977.

FOUCAULT, Michel. Microfísica do poder. Rio de Janeiro: Graal, 1979.

FOUCAULT, Michel. História da sexualidade I: a vontade de saber. Rio de Janeiro: Graal, 1999.

FOUCAULT, Michel. Sobre a história da sexualidade. In: FOUCAULT, Michel. Microfísica do poder. Rio de Janeiro: Graal, 2000. p. 243-276.

HERNÁNDEZ, Fernando. Cultura visual, mudança educativa e projeto de trabalho. Porto Alegre: Artmed, 2000.

HERNÁNDEZ, Fernando. Catadores da cultura visual. Tradução de Ana Death Duarte. Porto Alegre: Mediação, 2007.

MARX, Carl. Contribuição à crítica da economia política. 2. ed. São Paulo: Expressão Popular, 2008.

MIRZOEFF, Nicholas. Una Introducción a la cultura visual. Barcelona: Paidós, 2003.

SAUNDERS, Robert. A educação criadora nas artes. São Paulo: AR'TE, 1984.

STEINER, George. Extraterritorial: a literatura e a revolução da linguagem. São Paulo: Companhia das Letras, 1990. 


\section{Commerçants des sens: un regard sur la formation visuelle des apprenants}

\section{Résumé}

Cet article examine les possibilités qui la culture visuelle offre à la constitution des identités dans l'époque contemporaine. Il étudie le phénomène imagétique dans ce qui concerne le potentiel dialogique propre aux jeunes, sourtout comme une nouvelle et appropriée forme d'accès à la connaissance et, par consequence, à l'éducation formelle et non formelle, dans laquelle se comprend la culture de l'image comme un domaine qui offre de nouvelles possibilités pédagogiques et éducatives. Enfin, l'objective de cette étude est de permettre aux apprenants à jouer un rôle actif dans le complexe contexte du monde de l'image dans lequel les sujets sont toujours impliqués par leurs pratiques sociales. Nous avons suivi une perspective theorique et méthodologique de la culture visuelle selon quelques des plus importants auteurs dans ce domaine de connaisance. On a conclu qu'une éducation contemporaine, dans tous les niveaux et formes, exige formation pour la compréhension/lecture appropriée des images sous les formes les plus variées par lesquelles elles sont produites et diffusées, telle est sa force symbolique qui contribue à la formation des sujets.

Mots-clés: Éducation. Culture visuelle. Formation par des images.

\section{Senses Traders: a look at students' visual training}

\section{Abstract}

This article proposes to investigate the possibilities offered by visual culture in the constitution of identities in contemporary times. It studies the images universe in its familiar dialogical potential for young people, mainly as a new and adequate form of access to knowledge and, consequently, to formal and no formal education in which image culture is understood as a space that provides new pedagogicaleducational possibilities. This study also aims to contribute in order that students become able to play an active role in the context of a complex world of images which involves them, as subjects, for a long term in their social practices. Theoretically and methodologically we followed the perspective of visual culture in accordance with some of the main authors of this object. The study led us to conclude that a contemporary education of any level and form demands formation for an adequate understanding/reading of images under a wide variety of forms by which they are produced and widespread because of their symbolic force that contributes in the formation of subjects.

Keywords: Education. Visual culture. Formation by images. 


\section{Ireno Antônio Berticelli}

E-mail: ibertice@unochapeco.edu.br

\section{Claudia Aparecida dos Santos}

E-mail: claudiasartes@yahoo.com.br

\section{Valdecir Smaniotto}

E-mail:prof_smaniotto@yahoo.com.br

Enviado em: 17/7/2014 Aprovado em: 8/12/2014 